\title{
A Spectrographic Method
}

for Determining the Hafnium-Zirconium Ratio in Zircon

GEOLOGICAL SURVEY BULIETIN $1036-$ F

This report concerns work done on behalf of the U.S. Atomic Energy Commission and is published with the permission of the Commission

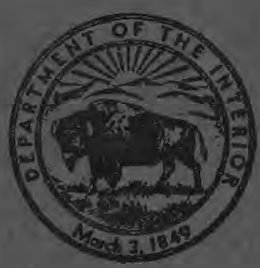





\section{A Spectrographic Method for Determining the Hafnium-Zirconium}

\section{Ratio in Zircon}

By C. L. WARING and H. W. WORTHING

A CONTRIBUTION TO GEOCHEMISTRY

GE O LO G I C A L S U R V E Y B ULLE T I N 1036-F

This report concerns work done on behalf of the U.S. Atomic Energy Commission and is published with the permission of the Commission

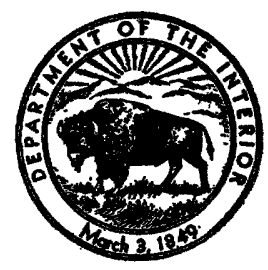




\title{
UNITED STATES DEPARTMENT OF THE INTERIOR \\ Douglas McKay, Secretary
}

\author{
GEOLOGIGAL SURVEY
}

Thomas B. Nolan, Director 


\section{CONTENTS}

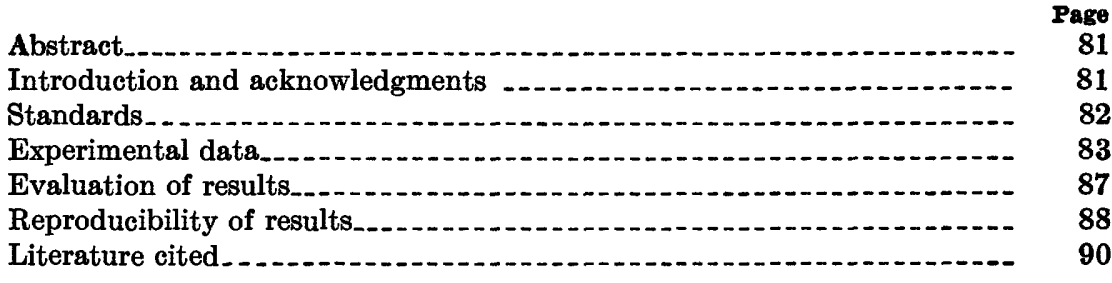

\section{ILLUSTRATIONS}

Figure 14. Working curve of hafnium-zirconium ratio in zircon

15. Hafnium working curve.......

16. Zirconium working curve 



\title{
A CONTRIBUTION TO GEOCHEMISTRY
}

\section{A SPEGTROGRAPHIC METHOD FOR DETERMINING THE HAFNIUM-ZIRCONIUM RATIO IN ZIRCON}

\author{
By C. L. WARING and H. W. WorthiNG
}

\section{ABSTRACT}

To develop a rapid spectrographic method for the determination of hafnium, the hafnium-zirconium ratio, and percentage of zirconium in the mineral zircon, the ratio was determined first by plotting the log of the intensity ratios against the log of the hafnium-zirconium ratio by weight of the standards, using zirconium as an internal standard (zirconium 2761.911 A and hafnium 2641.406 A or zirconium 2761.911 $\mathrm{A}$ and hafnium $2820.224 \mathrm{~A}$ ). Straight-line curves were produced when the line pairs zirconium 2538.405 $\mathrm{A}$ and hafnium $2641.406 \mathrm{~A}$ were used in a similar manner for the hafnium determinations. After the hafniumzirconium ratios and the hafnium percentages were determined, the zirconium percentages were determined arithmetically and some were checked by direct spectrographic analysis. When chemical methods were used to check the spectrographic hafnium and zirconium totals, an average spread of 0.14 was obeserved. The results indicated an average accuracy of 3 percent of the hafnium present in the range of 0.5 to 2.0 percent, and 0.6 percent for zirconium in the 43 to 58 percent range.

\section{INTRODUCTION AND ACKNOWLEDGMENTS}

In connection with a study of the radioactivity and geochemistry of minerals, rocks, and ores, a rapid spectrographic method was developed for the determination of the hafnium percentage, the hafnium-zirconium ratio, and the percentage of zirconium in the mineral zircon. The mineral samples were highly purified and had hafnium contents ranging from 0.1 percent to several percent; the zirconium ranged from 43 to 58 percent.

The published spectrographic methods for determining the percentage of hafnium and the hafnium-zirconium ratio have been reviewed by Ahrens (1950 p. 191-193). Many of these methods are applicable to rocks containing small amounts of zirconium and hafnium, after chemical concentration of these elements. The excellent method described by Mortimore and Noble (1953) was unsuitable for the complete problem at hand because the hafniumzirconium ratio was not included. Besides, the analysis of zirconium for hafnium with little or no silicon present and that of zircon with approximately 30 percent silicon would present different problems. 
The solution technique of Feldman (1949) was not suitable as a rapid method for determining hafnium and the hafnium-zirconium ratio because of the time and difficulty involved in dissolving the samples and preparing special electrodes. The method described by Fassel and Anderson (1950) also was not suitable to our problem because pure zirconium and pure hafnium oxide mixtures were used in pellet form. Our problem was to develop a rapid method (not including a pellet step) for the zircon mineral containing 30 percent silicon dioxide plus other impurities.

The method described here consists of arcing (d-c) to completion $1 \mathrm{mg}$ of the solid sample and the synthetic standards, mixed with three parts by weight of spectrographically pure graphite, processing the plate, obtaining the intensities of selected hafnium and zirconium lines by means of the densitometer, preparing percentage and emulsion calibration curves, and calculating the results.

The method as described is not applicable to rock samples containing small amounts of zirconium. The sensitivity of hafnium is approximately 0.01 percent and would not be detected in samples of lower zirconium content. It would be necessary either to separate the zirconium-containing minerals from the rock in order to apply the method or to improve the method in such a way as to increase the detection limit of the hafnium. Additional development work would be necessary to adjust the method to include the hafnium and hafnium-zirconium ratio of most rock samples.

The authors appreciate the help of their associates of the U. S. Geological Survey: Harry Levine and Roberta Smith made the chemical analyses, C. S. Annell prepared the pure silicon dioxide, $K$. Valentine did the semiquantitative spectrographic analysis of the chemical precipitates, and E. S. Larsen, Jr., and David Gottfried provided the samples. This study is part of a program conducted by the Geological Survey on behalf of the Division of Raw Materials of the U. S. Atomic Energy Commission.

\section{STANDARDS}

The chemicals used in preparing the synthetic standards were Specpure grade. The zirconium content of the hafnium oxide was certified as 1.5 percent. According to the manufacturer's directions for using the spectrographically standardized hafnium oxide for the determination of the zirconium content, a small portion of the sample was added to pure titanium dioxide. The zirconium was then determined quantitatively as a minor constituent in the titanium dioxide. The percentage of zirconium was confirmed by the U. S. Geological Survey laboratory by using as a standard the oxide of pure zirconium 
metal (40 ppm hafnium, $800 \mathrm{ppm}$ iron, $40 \mathrm{ppm}$ nitgrogen, remainder zirconium) supplied by the U. S. Bureau of Mines, Albany, Oreg.

A method of addition and extrapolation similar to that of Pierce and Nachtrieb (1941) was applied to the zirconium oxide to determine the hafnium content. Many tests were run and the average taken to establish the percentage of hafnium in the zirconium oxide as 0.1 percent. This result compared favorably with the one obtained by the semiquantitative method (Waring and Annell, 1953) which is based on standard plates prepared with Specpure chemicals and which has been used in the Geological Survey laboratory for the past four years.

The silicon dioxide was prepared from silica plate, heated to $600^{\circ} \mathrm{C}$, cooled quickly to fracture, ground to $100+$ mesh, leached in aqua regia, and washed with distilled water.

Standards were prepared by adding known amounts of iron, aluminum, calcium, and hafnium oxides to a mixture of 67 percent zirconium dioxide and 30 percent silicon dioxide. Iron, aluminum, and calcium were known to be present in highly purified zircon samples from the previous work of Larsen, Waring, and Berman (1953). The amount of the three oxides added to the standards varied according to the hafnium oxide, thus making the total percentage equal to 100 percent. The mixtures were ground in a boron carbide mortar to pass 100 -mesh stainless-steel screen. For more thorough mixing, the standards were passed repeatedly through 80 -mesh stainless-steel screen. Six standards were prepared with hafnium contents of $0.2,0.5,1.0,1.5$, 2.0, and 2.5 percent, after corrections for the hafnium originally present in the zirconium oxide.

\section{EXPERIMENTAL DATA}

The usual procedure here is to consume at least $10 \mathrm{mg}$ of sample in the arc for quantitative work. To consume completely this amount of the zircon mineral required a long period of burning because of the refractory nature of the zirconium. The long burning time of the $10 \mathrm{mg}$ sample resulted in excessive background. It was later established that results obtained by incomplete burns were low as compared to the zirconium-hafnium totals given by chemical analysis. Additional tests showed that $1 \mathrm{mg}$ of the sample mixed with three parts by weight of spectrographically pure graphite were completely consumed in the d-c arc in 180 seconds using a current of 12 amperes. We found, as Feldman (1949) did, that the log of the intensity ratios plotted against the log of the hafnium-zirconium ratios by weight of either of two line pairs of the standards produced straight-line curves that were considered satisfactorv for determining the concentration 


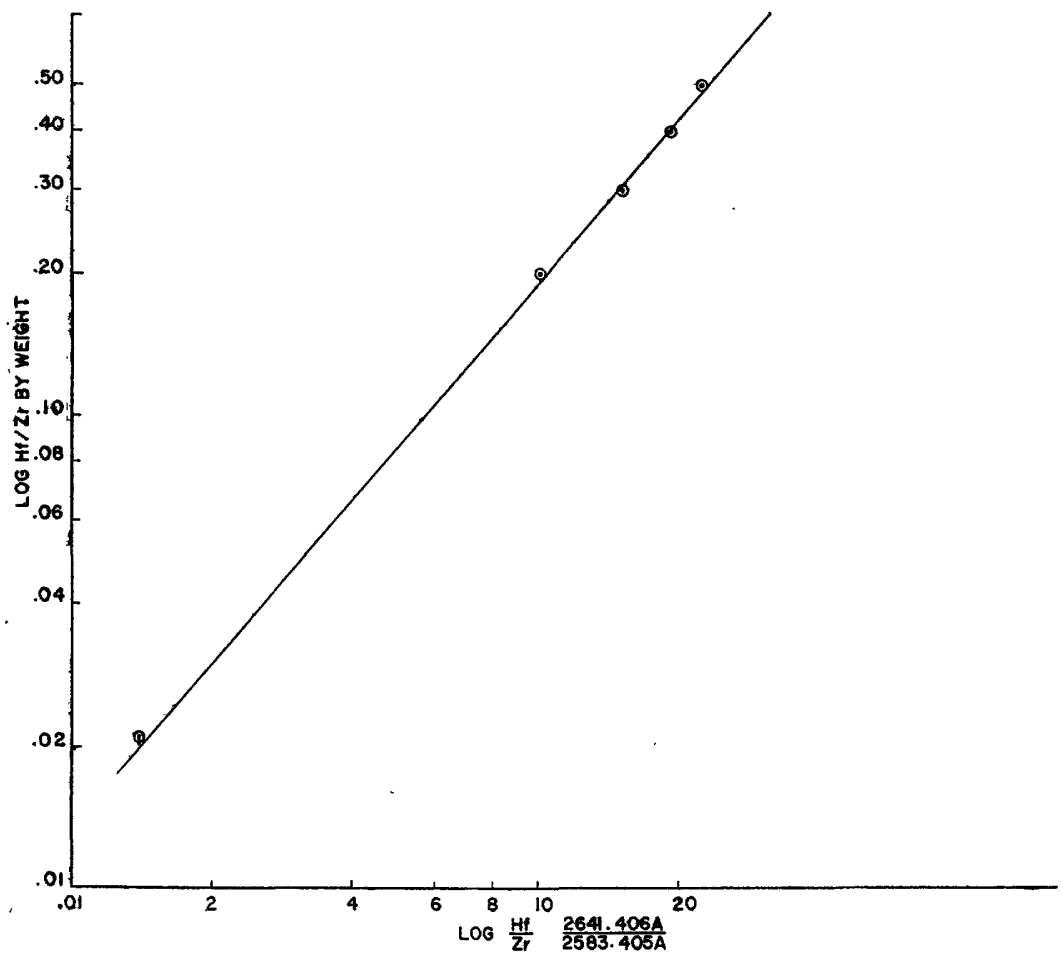

Foure 14.-Working curve of hafnium-zirconium ratio in zircon.

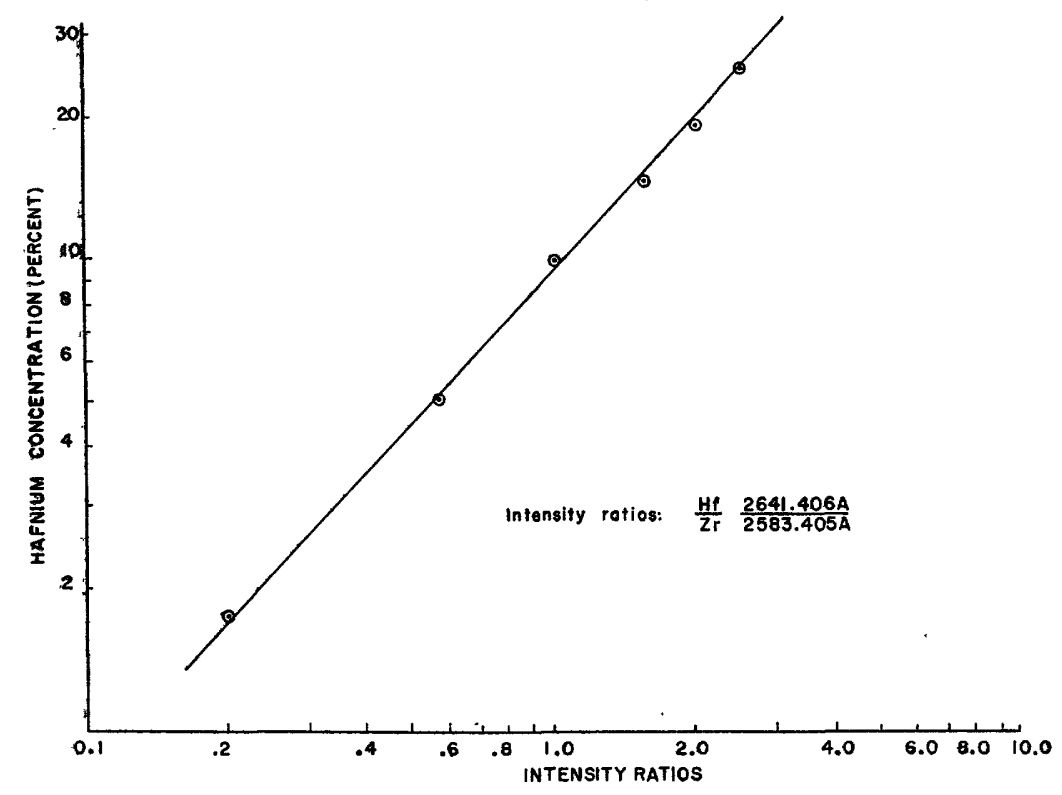

Frove 15.-Hafnium working curve. 
ratios. These line pairs were zirconium $2761.911 \mathrm{~A}$ and hafnium 2641.406 A, and zirconium 2761.911 $\mathrm{A}$ and hafnium 2820.224 A. Straight-line curves were produced when the spectral lines zirconium 2538.405 A and hafnium 2641.406 A were used to plot the log of the intensity ratios against the log percentage concentration of hafnium for the hafnium determinations. The intensity ratios of the transmittance values were obtained by using the emulsion calibration curve. The intensity ratios were applied to the working curves to determine the concentrations. No background corrections were necessary because the background was insignificant. Figures 14 and 15 show typical examples of these curves.

In the early part of the work the ratio was determined first by plotting the $\log$ of the intensity ratios against the $\log$ of the hafniumzirconium ratio by weight of the standards, using zirconium as an internal standard. Straight-line curves were produced when the same line pairs (zirconium 2538.405 $\mathrm{A}$ and hafnium 2641.406 A) were used in a similar manner for the hafnium determinations. However, when chemical methods were used to check the spectrographic and zirconium totals, an apparent bias of $+1.87^{\circ}$ was observed. Tests were continued to eliminate this bias. It was found that increasing the graphite to three parts instead of two, cutting the cup of the lower electrode deeper, and using zirconium 2761.911 A with hafnium 2641.406 A or zirconium 2761.911 A with hafnium $2820.224 \mathrm{~A}$ for the ratio curves and zirconium 2538.405 A with hafnium 2641.406 A for the hafnium curves, eliminated the bias.

As a check on the calculated zirconium values additional experimental work was done. Simulated samples (see table below) were arced under the previously described spectrographic conditions (intensity decressed from 100 percent to 25 percent). A zirconium working curve was prepared and three additional synthetic samples were analyzed for zirconium (zirconium $2761.911 \mathrm{~A}$ ) without an internal standard line. The results are as follows (see working curve, fig. 16): 
Comparisons of spectrographic and calculated percentages of hafnium and zirconium in simulated zircon samples

\begin{tabular}{|c|c|c|c|c|c|c|c|}
\hline \multirow{2}{*}{ Sample } & \multirow{2}{*}{ Element } & \multicolumn{3}{|c|}{ Spectrographic percentage } & \multirow{2}{*}{$\begin{array}{l}\text { Calculated } \\
\text { percentage }\end{array}$} & \multicolumn{2}{|c|}{ Difference } \\
\hline & & Added & Found & Ratio & & $\mathrm{Zr}$ & Ht \\
\hline $\mathbf{s}-1$ & $\mathbf{Z r}$ & 43 & & & 43. 5 & 0.5 & \\
\hline 1 & Hf & .5 & 0.48 & 0.0110 & & $-n$ & 0.02 \\
\hline 2 & $\mathbf{Z r}$ & 48 & - & .......... & 48. 3 & .3 & $\ldots$ \\
\hline 2 & Hf & 1. 0 & 1. 05 & .0216 & $\ldots$ & _... & .0 \\
\hline 3 & $\mathbf{Z r}$ & 53 & $\ldots$ & - & 53. 4 & .4 & $\ldots$ \\
\hline 3 & Hf & 1. 5 & 1. 55 & .0290 & - & & .05 \\
\hline 4 & $\mathbf{Z r}$ & 58 & 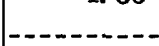 & - & 58 & .0 & - - - \\
\hline 4 & Hf & 2. 0 & 1. 97 & .0340 & & & .03 \\
\hline \multicolumn{3}{|l|}{ Sample } & \multicolumn{2}{|l|}{ Element } & \multicolumn{2}{|c|}{$\begin{array}{c}\text { Added } \\
\text { (percent) }\end{array}$} & $\underset{\text { (porcent) }}{\text { Found }}$ \\
\hline $\mathbf{S}-5$ & irconium & -- &.- & $-\ldots$ & - & 45 & 45. 1 \\
\hline 6 & irconium & - & $-\ldots$ & 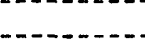 & - & 50 & 49.9 \\
\hline 7 & lirconium & 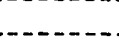 & ............ & - - & - n & 55 & 55.0 \\
\hline
\end{tabular}

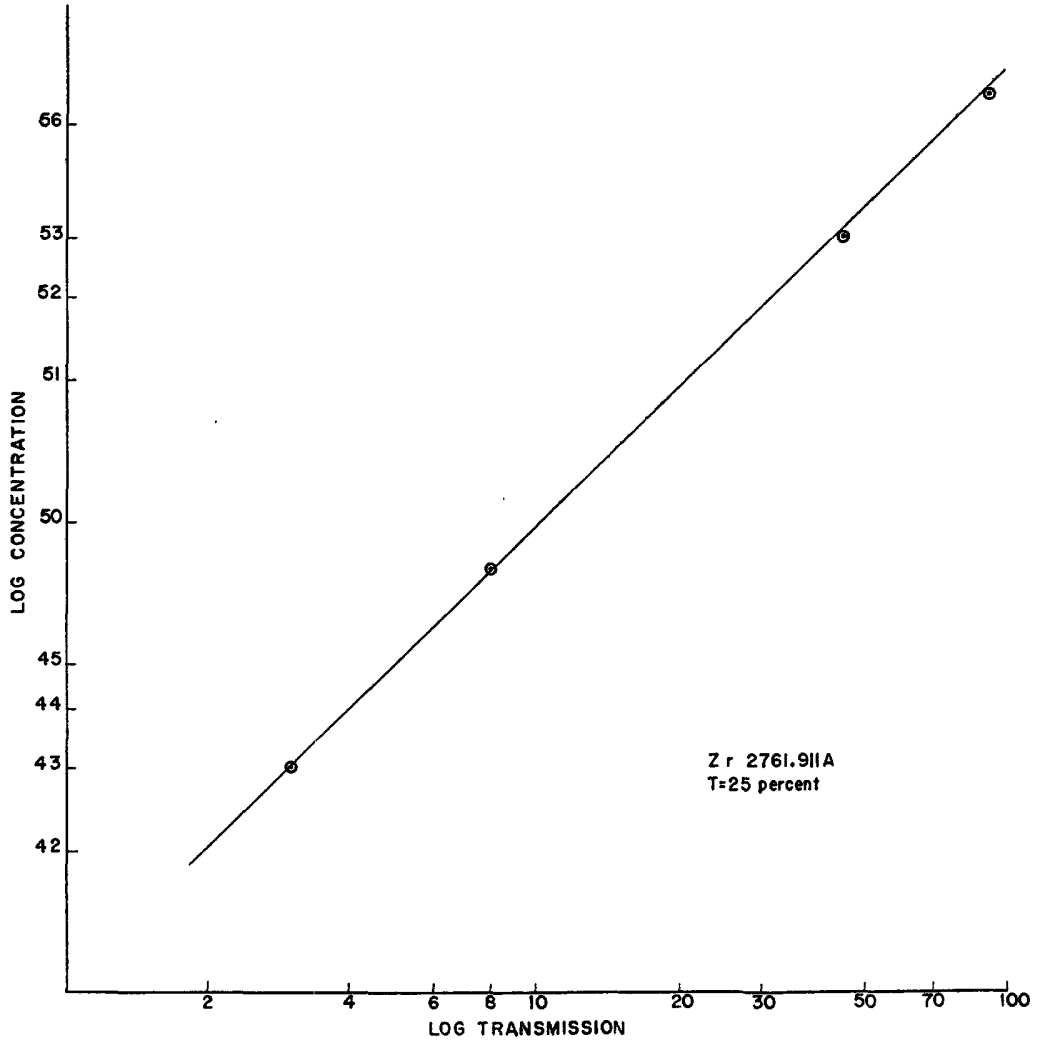

Fioure 16.-Zirconium working curve. 
The hafnium-zirconium ratios could be determined by analyzing for hafnium and zirconium independently, or by the simpler way of using a ratio curve.

The emulsion calibration curves were prepared by the two-step. method described by Harvey (1950, p. 76-78).

The following experimental conditions were used:

Excitation source: multisource d-c arc. This procedure can utilize any $\mathbf{3 0 0}$ volt d-c prower source where the operating discharge value remains stable at 12 amperes and 300 volts.

Resistance: 15 ohms.

Initiator: high.

Phase: 0 .

Strike: strike position.

Amperes: 12.

Spectrograph: 21-foot Wadsworth-mounted grating.

Slit: 25 microns.

Optics: total arc image focused on collimating mirror; a thin crystal quartz cylindrical lens covered slit; no apparent imaging on slit.

Emulsion: SA-1, plates, Eastman.

Development: 5 minutes at $18^{\circ} \mathrm{C}, \pm 1 / 2^{\circ} \mathrm{C}, \mathrm{D}-19$.

Arc gap: 4 to $6 \mathrm{~mm}$, gap adjusted to marked positions on outside target.

Transmission: 100 percent.

Arcing time: 3 minutes.

Spectrum: first order.

Electrode, lower: carbon, spectroscopie carbons, $1 / 4$ in., cut to outside diameter 0.22 in., depth of shoulder 0.12 in., inside diameter 0.19 in., depth of crater 0.20 in.

Electrode, upper: carbon, spectroscopic carbons, 1/4 in., hemispherical, 0.06in. radius.

\section{EVALUATION OF RESULTS}

Eight samples were analyzed chemically by two methods for their content of zirconium and hafnium. The first chemical method (Hillebrand and Lundell, 1953 , p. 567), precipitation by $n$-propylarsonic acid, gave precipitates with a high content of impurities, as shown by spectrographic analysis. Chemical precipitates, produced by the mandelic acid. precipitation method (Kumins, 1947), were tested spectrographically and showed aluminum, iron, and magnesium in the 0.1 to 0.05 percent range, barium in the 0.005 to 0.01 percent range, and manganese in the 0.0005 to 0.001 percent range. Results given by the mandelic acid precipitation method were selected for comparison with the spectrographic results because of the high purity of the precipitates. These comparisons are shown below. The data may be supplemented by reference to Fleischer's work (1955). 


\section{LITERATURE CITED}

Ahrens, L. H., 1950, Spectrochemical anaylsis, Cambridge, Mass., Addison-Wesley Press, Inc., p. 191-193.

Fassel, V. A., and Anderson, C. H., 1950, Quantitative spectrographic analysis of zirconium-hafnium mixture: Optical Soc. America Jour., v. 40, p. 742-747.

Feldman, C., 1949, Spectrochemical determination of hafnium-zirconium ratios: Anal. Chemistry, v. 21, p. 1211-1215.

Fleischer, Michael, 1955, Hafnium content and hafnium-zirconium ratio in minerals and rocks: U. S. Geol. Survey Bull. 1021-A, p. 1-13.

Harvey, C. E., 1950, Spectrochemical procedures, Glendale, Calif., Applied Research Laboratories.

Hillebrand, W. F., and Lundell, G. E. F., 1953, Applied inorganic analysis, 2d ed., New York, John Wiley and Sons.

Kumins, C. A., 1947, Zirconium determination in the presence of interfering elements: Anal. Chemistry, v. 19, p. 376-377.

Larsen, E. S., Jr., Waring, C. L., and Berman, J., 1953, Zoned zircon from Oklahoma: Am. Mineralogist, v. 38, p. 1118-1125.

Mortimore, D. M., and Noble, L. A., 1953, Determining low concentrations of hafnium in zirconium: Anal. Chemistry, v. 25, p. 296-298.

Pierce, W. C., and Nachtrieb, N. H., 1941, Photometry in spectrochemical analysis: Indus. and Eng. Chemistry, Anal. ed., v. 13, p. 774-781.

Waring, C. L., and Annell, C. S., 1953, Semiquantitative spectrographic method for analysis of minerals, rocks, and ores: Anal. Chemistry, v. 25, p. 11741179. 




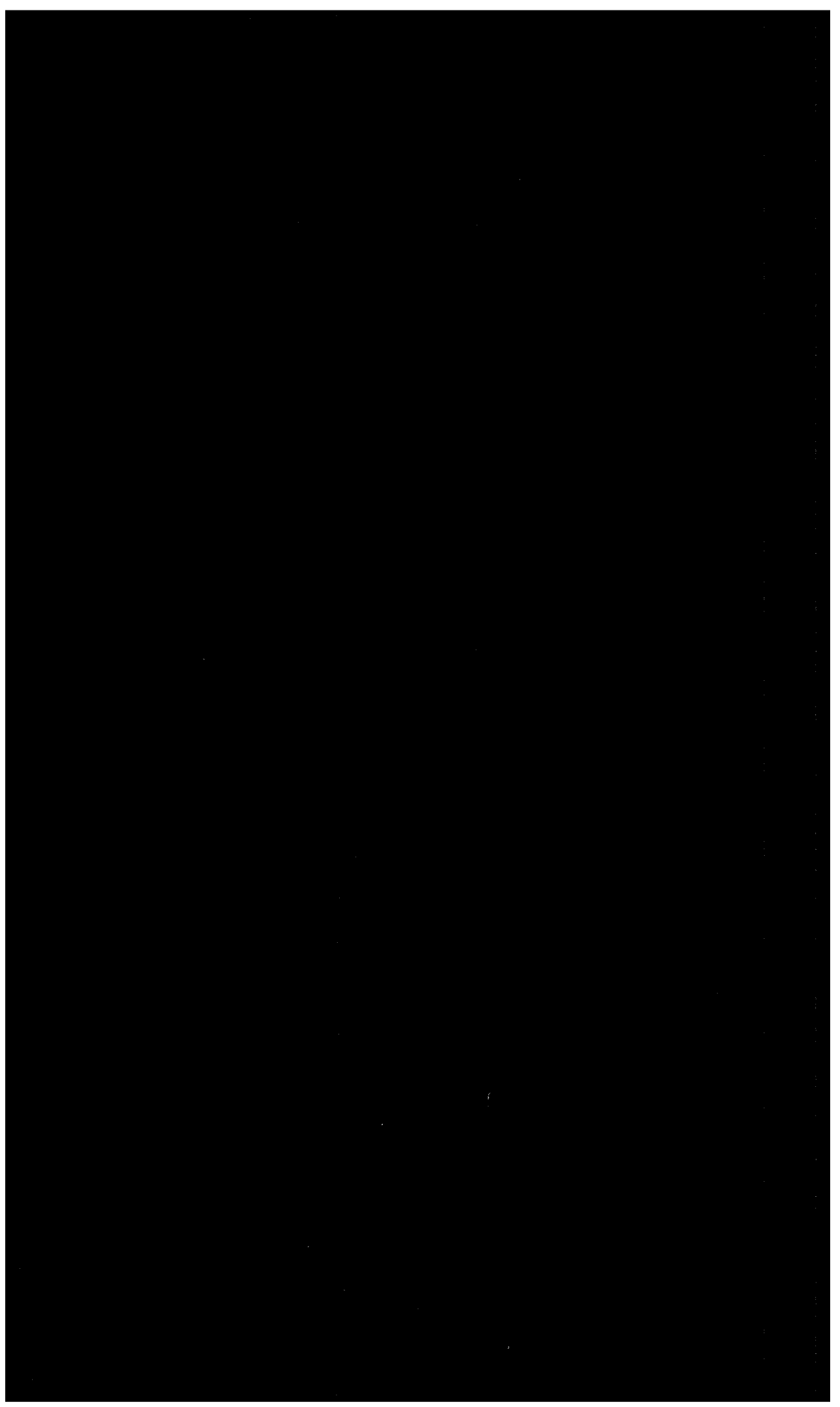




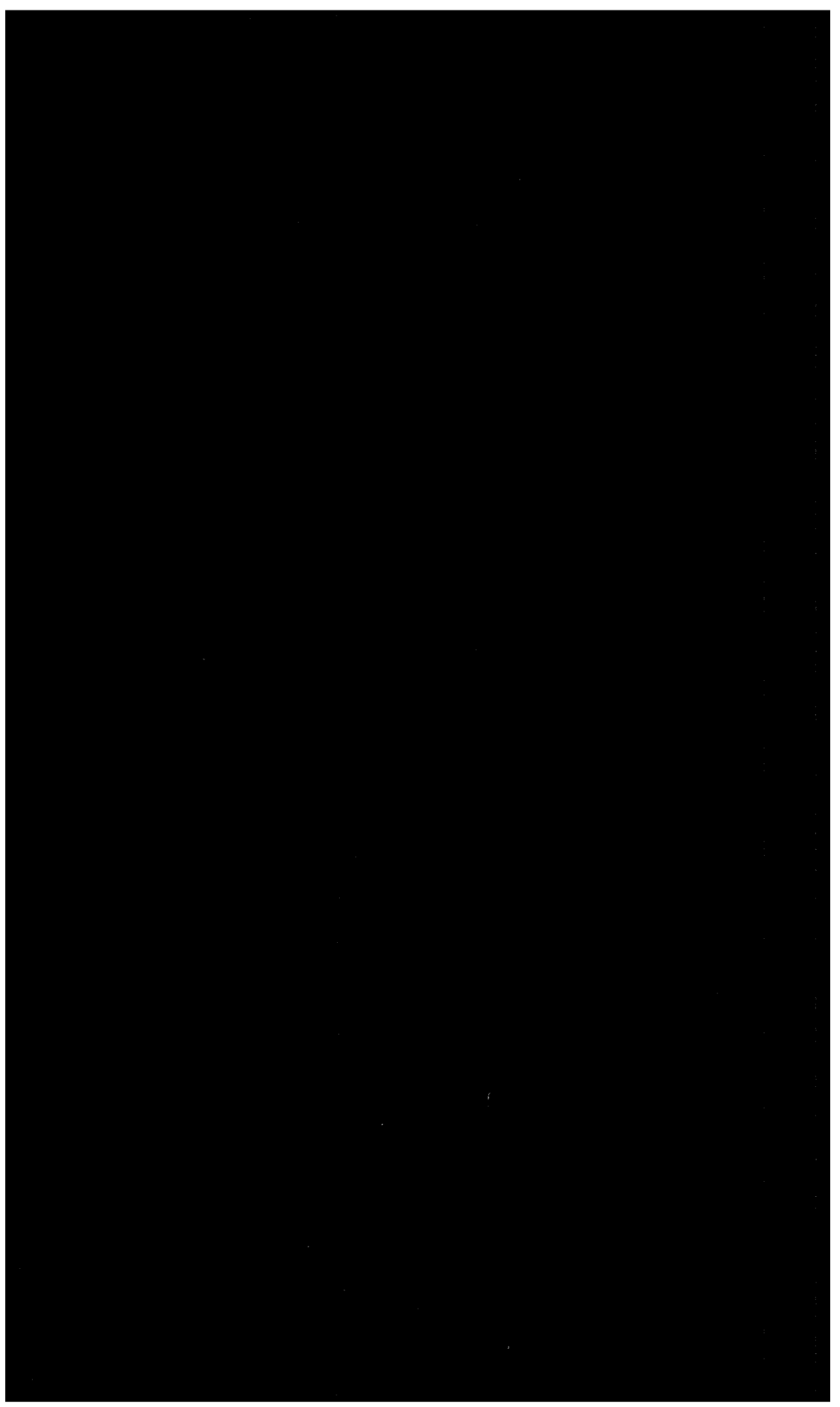

